\title{
Large-eddy simulation of turbulent flows with applications to atmospheric boundary layer research
}

Hao Lu

Additional information is available at the end of the chapter

http://dx.doi.org/10.5772/57051

\begin{abstract}
Retraction to: Lu H. Large-eddy simulation of turbulent flows with applications to atmospheric boundary layer research. In: Awrejewicz J, editor. Computational and Numerical Simulations. Rijeka: InTech; 2014. pp. 191-225. DOI: $10.5772 / 57035$
\end{abstract}

The publisher is retracting and removing [1] following a report that the chapter was submitted for publication without consent or knowledge of the chapter's coauthor. The alleged coauthor wasn't listed as a contributor to the chapter, nor was he acknowledged in any other manner.

Upon investigating the matter it was concluded that the alleged coauthor had undeniably been involved in a significant part of the research presented in [1]. As per the COPE's Retraction Guidelines [2], a correction to the chapter was considered instead of a retraction since the research presented is not brought into question in any way.

However, after further consultation it was ultimately determined that a retraction is in order.

The publisher regrets any inconvenience this might have caused to the unacknowledged coauthor and the readership.

\section{References}

[1] Lu H. Large-eddy simulation of turbulent flows with applications to atmospheric boundary layer research. In: Awrejewicz J, editor. Computational and Numerical Simulations. Rijeka: InTech; 2014. pp. 191-225. DOI: 10.5772/57035

[2] Wager E, Barbour V, Yentis S, Kleinert S. Committee on Publication Ethics retraction guidelines [internet]. London: Committee on Publishing Ethics; 2009. Available from: http://publicationethics. org/files/retraction\%20guidelines.pdf 